\title{
Inserção de tecnologias digitais nas práticas avaliativas: uma leitura semiótica da plataforma educacional Additio
}

\author{
Poliana Sabina Quintiliano Silvesso ${ }^{1}$ \\ Sueli Maria Ramos da Silva²
}

\section{Resumo}

Dentre as práticas pedagógicas comuns ao ambiente escolar e diante das mudanças tecnológicas, selecionamos para este trabalho a avaliaçáo da aprendizagem e as ferramentas digitais que podem ser usadas como facilitadoras do processo avaliativo. O objetivo geral do artigo é trazer reflexôes importantes sobre a avaliação. Inicialmente, trazemos concepções dicionarizadas sobre avaliação, atribuindo um viés semiótico para o termo. As últimas discussóes teóricas que formulam sobre diversos tipos avaliativos também são alvo deste artigo e podem ser corroboradas com as proposiçóes teóricas de diversos teóricos do campo da educação. O objetivo específico do artigo é analisar semioticamente a interface da plataforma educacional Additio, uma ferramenta de gestão escolar que permite a inserção de diversos tipos de avaliação por meio do seu sistema de rubricas. O ferramental teórico escolhido para essa análise é a semiótica discursiva e plástica de linha greimasiana. Primeiro, observamos o plano da expressáo e apresentamos a plataforma, sua interface e analisamos seus espaços de usuário, tais como: página de login, página inicial, sistemas internos de cadastramento de alunos, notas e avaliaçóes. Em seguida, mostramos como acontece a interaçáo sujeito e plataforma, colocando em evidência os arranjos modais do plano do conteúdo. Os resultados aferidos demonstram como as ferramentas digitais facilitam o fazer pedagógico docente e oportunizam o uso de avaliaçôes diversificadas.

Palavras-chave: avaliação; objetivos afetivos; avaliação da afetividade; semiótica discursiva.

\section{Insertion of digital technologies in evaluation practices: a semiotic reading of the educational platform Additio}

\section{Abstract}

Among the pedagogical practices common to the school environment and technological changes, we selected for this work the evaluation of learning and the digital tools used as facilitators of the evaluation process. The main objective of the article is to bring important reflections on the evaluation. Initially, we bring conceptualized conceptions about evaluation,

1 Mestre pelo Programa de Pós-graduação (mestrado e doutorado) em estudos de linguagens da Universidade Federal de Mato Grosso do Sul (UFMS). E-mail: polianasilvesso@gmail.com.

2 Doutora em Semiótica e Linguística Geral pela Universidade de São Paulo (USP), professora adjunta da Universidade Federal de Mato Grosso do Sul (UFMS). E-mail: sueli.silva@ufms.br. 
assigning a semiotic bias to the term. The last theoretical discussions that formulate on several types of evaluation are also the subject of this article and can be corroborated with the theoretical propositions of several theorists of education. The specific objective is to analyze semiotically the interface of the educational platform Additio, a school management tool that allows the insertion of several types of evaluation through its system of rubrics. The theoretical tool chosen for this analysis is the discursive and plastic semiotics of the greimasian line. First, we look at the expression plane and present the platform, its interface and analyze its user spaces, such as: login page, home page, internal student enrollment systems, grades and assessments. Next, we show how the subject and platform interaction happens, specially the modal arrangements of the content plane. Finally, the results show how the digital tools facilitate teacher's work and the use of diversified assessments.

Keywords: evaluation; affective objectives; assessing affective domain; discursive semiotic.

\section{Introduçáo}

As discussóes deste artigo se coadunam aos diversos questionamentos levantados pelos professores da educação básica, principalmente sobre as práticas que envolvem a elaboração de provas e o sistema avaliativo adotado pelas escolas, geralmente. Os questionamentos sobre avaliação, presentes neste artigo, são objeto de formulaçóes teóricas de diversos autores da educação, tais como Suassuna (2007), Luckesi (2011), Martins, Racilan e Souza (2012) e Moretto (2014), ao abordarem os paradigmas da avaliaçáo no sistema educacional vigente.

Diante disso, o objetivo geral do artigo é trazer essas reflexóes teóricas sobre as práticas avaliativas comuns ao meio escolar, evidenciando perfis avaliativos mais convencionais, ou seja, tradicionalmente inseridos no sistema educacional. Configura-se, inicialmente, uma discussão em torno do termo avaliação, em que apresentamos definiçôes encontradas em dicionários de uso comum da língua e no dicionário de semiótica, a fim de associá-la a um valor formativo. Demonstramos ainda, como cada eixo avaliativo pode compor as práticas pedagógicas nos diferentes estágios da aprendizagem.

Acompanham as formulaçóes presentes, o uso de objetivos afetivos nas práticas pedagógicas. Tradicionalmente, alguns teóricos do campo da educação, tais como Bloom, Krathwohl e Masia (1973), dividem os objetivos educacionais em três domínios: cognitivo, afetivo e psicomotor. Para esses autores, os objetivos cognitivos se mostram mais fáceis de trabalhar, pois, de forma geral, professores tem mais facilidade em quantificar o desempe- 
nho cognitivo dos alunos. No entanto, ao refletirem sobre as habilidades afetivas, acabam frustrados, dada a dificuldade em se atribuir uma nota. É então que as tecnologias digitais voltadas para a educação passam a cumprir papel fundamental no processo avaliativo, já que, em alguns casos, otimizam o tempo de planejamento, facilitam o trabalho com diversas avaliaçóes, permitem acompanhar o desempenho dos alunos e, ainda, trabalhar com objetivos afetivos. Por isso, escolhemos como objeto de análise a plataforma educacional Additio, uma ferramenta de gestáo de sala de aula.

A plataforma possibilita o cadastramento de diferentes tipos de avaliação, por meio do seu sistema de rubricas. Ela permite, também, a configuração de diferentes tipos de notas, seja a simples atribuição numérica e de conceitos, até o uso de escalas de cores e ícones. Dentre os recursos que a plataforma dispóe, mostramos como seu sistema de rubricas possibilita o trabalho com objetivos do campo afetivo, o que vai em direção às discussões formuladas neste artigo. Outras plataformas educacionais também oferecem recursos semelhantes, como as plataformas Guten news, Google classroom, Class dojo, Teacher kit, entre outros, porém, os recursos são limitados quanto ao cadastro de avaliaçóes, ou estão focados em avaliações do domínio cognitivo, que não são o foco principal deste trabalho.

Para análise da plataforma, elegeu-se como fundamentação teórica a semiótica discursiva e a semiótica plástica, desenvolvida por Floch (1972). Esta última porque em suas proposiçóes contempla os elementos imagéticos, importantes à essa análise. Metodologicamente, mostramos como as cores, ícones e outros elementos presentes no layout conversam com o enunciatário. Assim, analisamos o espaço de login, a página inicial, o cadastramento de alunos e o cadastramento de notas, utilizando três categorias: cromática, eidética e topológica. Esperamos, com isso, justificar o uso de tecnologias digitais nas práticas pedagógicas, em especial, como facilitadoras das práticas avaliativas, de forma que dialogue com as discussóes levantadas sobre os paradigmas da avaliação escolar.

\section{Avaliação numa perspectiva semiótica}

Em sua concepção mais simples, a noção de avaliação possibilita uma reflexão importante sobre como tal prática no ambiente escolar é distante do sentido comum que a palavra carrega. A esse respeito, apontemos o que esclarecem Ferreira e Leal: 
Quando temos que tomar uma decisão importante, pensamos muitas vezes, antes, se tal escolha é a mais acertada, se este é o momento certo, se estamos agindo apenas com o coração ou com a razão, se adotamos as melhores estratégias, se os resultados de nossas açóes foram os que esperávamos que fossem etc. Não é apenas em momentos tão marcantes de nossas vidas, como quando decidimos casar, ter um filho ou escolher uma profissão, por exemplo, que fazemos escolhas e que ponderamos as nossas açóes. Até uma simples ida ao comércio nos coloca em situação de alerta para as nossas escolhas. (FERREIRA; LEAL, 2007, p. 11).

Se a avaliação é um ato de ponderar sobre escolhas que iremos fazer e sobre quais decisóes tomar, o seu propósito em ambiente escolar deve nortear as abordagens do professor e de toda a comunidade escolar. Nesse caso, a fim de entender melhor o que caracteriza a avaliação escolar, procuramos algumas definiçóes formais para o termo.

Ao realizar uma busca sobre o vocábulo "avaliar" nos dicionários Dicio e Michaellis, a definição do termo, em ambos os dicionários, apresenta certas semelhanças. Entretanto, o dicionário Michaellis fornece definiçóes mais detalhadas e completas. As cinco entradas apreciadas pelo dicionário Dicio são: "1. Determinar o valor de; 2. Compreender; 3. Apreciar, prezar; 4. Reputar-se; 5. Conhecer o seu valor.” (DICIO, 2018). No Michaellis, temos:

Calcular ou determinar o valor, o preço ou o merecimento de [...]; 2. Reconhecer a intensidade, a força de [...]; 3. Apreciar o valor de algo ou alguém [...]; 4. Fazer o cômputo de, calcular, computar, orçar [...]; 5. Supor previamente, julgar segundo certas probabilidades; pressupor, presumir [...]. (MICHAELLIS, 2018, s/p).

Em aproximação com as práticas pedagógicas, a primeira definição "determinar o valor de", bem como as definiçôes "compreender, julgar", parecem mais adequadas ao contexto escolar. Já o termo "analisar", também observado nesses mesmos dicionários, pelas semelhanças que possui com o vocábulo “avaliar", sugere uma relação sinonímica. No dicionário Dicio (2018), encontramos os seguintes significados: “1. Fazer análise de; 2. Examinar com atenção; 3. Criticar”, no Michaellis, as entradas são:

Fazer análise de; decompor um todo em suas partes constituintes ou fundamentais [...]; 2. Investigar ou examinar minuciosamente; esquadrinhar, dissecar [...]; 3. Discutir o valor de (alguém ou algo), verificando qualidades e defeitos; comentar, criticar, ponderar [...]; 
4. Decompor uma unidade linguística (palavra, frase, oração, período, texto etc.) em seus elementos mínimos para descrição e classificação [...]; 5. Examinar(-se) ou submeter (-se) a análise; apreciar(-se), estudar(-se); 6. Psicanalisar. (MICHAELLIS, 2018, s/p).

Retomemos a terceira definição do dicionário Michaellis, “3. Discutir o valor de (alguém ou algo), verificando qualidades e defeitos; comentar, criticar, ponderar", já que o ato pedagógico de avaliar pressupóe a discussão e ponderação do valor das produçóes escolares, sejam elas do âmbito cognitivo, afetivo ou psicomotor. $O$ primeiro termo também constitui parte essencial desse processo, a postura do professor diante das produçóes do alunado é de análise, pressupondo crítica, comentário, verificação de qualidades e defeitos, como elencado no item 3 do dicionário.

Para suscitar as devidas distinçóes, tomada a perspectiva semiótica, recorremos ao termo "análise", presente no Dicionário de semiótica, em que é definido como "o conjunto de procedimentos utilizados na descrição de um objeto semiótico” (GREIMAS; COURTÉS, 1979, p. 20). O objeto semiótico discutido no âmbito da avaliação escolar, e que ainda vai se delineando à medida em que aprofundamos nossas discussóes, é a qualidade das produçóes e comportamentos do aluno, contemplando os domínios de aprendizagem já referidos. O objeto indica para quem avalia e para quem é avaliado as competências que foram internalizadas no processo de ensino-aprendizagem, as decisóes que devem ser tomadas e ainda a revisão e consolidação das propostas curriculares (MARCUSCHI, 2006 apud CARVALHO, 2018, p. 54).

Caminhando um pouco mais, cabe também a averiguação dos vocábulos "descrição" e "procedimentos". O primeiro, de difícil definição nos termos do dicionário de semiótica, pode ser entendido como "uma atividade que consiste na construção de uma linguagem descritiva" (GREIMAS; COURTÉS, 1979, p. 111) - uma definição mais pertinente para o estudo que se faz sobre avaliação da aprendizagem. O segundo vocábulo, é referido da seguinte maneira: "entende-se por procedimento uma sequência de operaçóes ordenada, que visa a esgotar a descrição de um objeto semiótico, segundo o nível de pertinência escolhido" (GREIMAS; COURTÉS, 1979, p. 20).

Ao relacionar essas definiçóes, fica evidente que o trabalho de avaliar não é uma tarefa facilmente executável. Descrever o objeto semiótico, indica ao nosso ver, fazer o uso de procedimentos claros, ou seja, ter em mente uma sequência de operaçóes que guiará a análise. O nível de pertinência esco- 
lhido, como descrito no dicionário, aponta para os objetivos traçados pelo professor, e dizem respeito às habilidades cognitivas, afetivas e psicomotoras mobilizadas pelo aluno quando ele estuda situaçóes complexas propostas em sala de aula (MORETTO, 2014, p. 21). É nessa direção que o conhecimento sobre as diferentes concepções e funções da avaliação, presentes na tradiçáo desses estudos, auxilia na escolha de procedimentos avaliativos.

\section{MODALIDADES DE AVALIAÇÃO E SEUS RECURSOS}

No âmbito dos estudos sobre avaliação, observando-se aspectos relacionados às metodologias, concepçōes, funções e objetivos, alguns estudiosos compreendem, hoje, a coexistência de dois grandes paradigmas: um paradigma tradicional e outro de caráter formativo. O primeiro reconhece-se pela competitividade, classificação, quantização do conhecimento e meritocracia. O segundo é caracterizado por atitudes democráticas e por uma concepçáo de aprendizagem ampla, ou seja, que abarque todo o processo de aprendizagem (SUASSUNA, 2007, p. 27-28).

Dentre as problemáticas suscitadas pelo paradigma tradicional estão os testes padronizados e os resultados quantitativos obtidos destes (SUASSUNA, 2007, p. 32), de forma que a única habilidade exigida é a de recordar. Assim, o sistema avaliativo enfoca um poder-fazer do sujeito, cujo objeto de valor são as pontuaçóes atribuídas ao longo do ano escolar, sem preocupação com o amadurecimento dos conteúdos internalizados ou com habilidades que superem às ligadas a cognição. Além disso, a avaliação deixa de cumprir seu papel diagnóstico quando a escola a utiliza como ato de verificar:

A verificação encerra-se no momento em que o objeto ou ato de investigação chega a ser configurado, sinteticamente, no pensamento abstrato [...] A dinâmica do ato de verificar encerra-se com a obtenção do dado ou informação que se busca, isto é, "vê-se" ou "não se vê" alguma coisa. E...pronto! Por si, a verificação não implica que o sujeito retire dela consequências novas e significativas. (LUCKESI, 2011, p. 92).

É evidente que temos diante de nós uma cultura escolar observadora da avaliação somativa - aqui entendida como avaliação tradicional, utilizada para comprovar se determinados conteúdos ao longo do bimestre ou do ano letivo foram memorizados pelos alunos, como referido no parágrafo anterior. Essa forma de avaliar, comum ao ambiente escolar, é prejudicial a 
o todo sistema educacional (aluno, professor, comunidade escolar) quando utilizada com exclusividade durante o processo avaliativo. É certo que a prova, o recurso mais utilizado no contexto da avaliação somativa, ainda é parte do dia a dia do professor. Sem muitas chances de se desvincular dela, cabe, conforme Moretto (2014), ressignificar o instrumento e elaborá-la dentro de uma nova perspectiva pedagógica. É nesse sentido que a prova pode ser integrada ao segundo paradigma da avaliação.

No segundo paradigma, observamos dois tipos de avaliação: a avaliação diagnóstica e a avaliação formativa. A primeira é utilizada pelos professores com o objetivo de averiguar os conhecimentos prévios dos alunos, assim, quando o professor planeja suas aulas, consegue estabelecer objetivos que contemplem esses conhecimentos, podendo avançar ou retomar determinados conteúdos. A avaliação formativa, por sua vez, fornece ao professor informaçóes sobre a forma como os alunos entendem e aplicam os conhecimentos adquiridos em sala de aula (BRAGA, 2012).

Uma forma de tornar o processo avaliativo mais eficiente, é por meio da inserçáo de tecnologias digitais em sala de aula. Observar o desenvolvimento de alunos ao longo de um bimestre ou de um ano demanda bastante esforço do professor. Com turmas cheias, e ainda tendo que lidar com aspectos burocráticos que o ambiente escolar impóe, essa tarefa torna-se desmotivadora para o professor. Entretanto, a utilização de apps educacionais, ambientes virtuais de interação entre alunos e professores, entre outros recursos digitais, propicia momentos mais colaborativos, bem como diminui o acúmulo de atividades impressas, e auxilia no monitoramento das atividades realizadas.

Sobre isso, Martins, Racilan e Souza (2012, p. 196) afirmam que

A tecnologia pode desempenhar um papel importante no processo avaliativo, ajudando os professores a atender às necessidades individuais dos alunos e possibilitando que os próprios estudantes monitorem seu progresso. $\mathrm{O}$ uso da tecnologia não só é capaz de proporcionar ao professor um acompanhamento regular do progresso de todos os alunos, mas ainda de permitir que estes acompanhem o trabalho e o desenvolvimento de seus colegas.

Diante da possibilidade de uso de ferramentas tecnológicas, especialmente virtuais, a avaliaçáo formativa ganha mais espaço. Contudo, é necessário uma ressalva. A avaliação em abiente virtual não significa que 
uma prova será realizada por meio de um computador, como muitos podem pensar. As tecnologias digitais permitem o desenvolvimento de atividades as mais diferenciadas, e também podem ser usadas como ferramentas de gestão escolar. Entre as técnicas, destacam-se "a observação e fichas (ou listas de controle, escalas sistemas de categorias.; [...] entrevista e questionário; a técnica sociométrica e sociograma; [...] a técnica da testagem (exame, verificação) e teste objetivo e de ensaio" (SANT'ANNA et al., 1993, p. 195). Entendemos por técnica, os procedimentos utilizados para aferir habilidades internalizadas pelo alunado. Um quadro elaborado pelas autoras, ilustra melhor as possibilidades avaliativas para cada domínio:

Quadro 1 - Instrumentos e recursos da avaliação

\begin{tabular}{|c|c|c|c|}
\hline $\begin{array}{l}\text { Objetivos } \\
\text { (domínio) }\end{array}$ & $\begin{array}{l}\text { Modalidades } \\
\text { de avaliação }\end{array}$ & Técnica aconselhada & Instrumentos e recursos \\
\hline \multirow{7}{*}{ 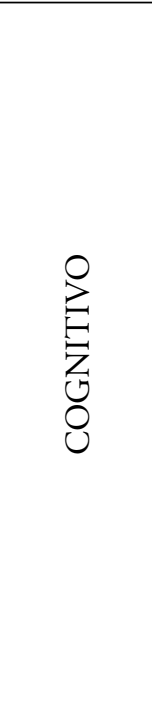 } & \multirow{3}{*}{ 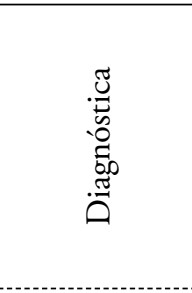 } & Observação & $\begin{array}{c}\text { escalas, sistema de } \\
\text { categorias, anedotários, } \\
\text { fichas etc. }\end{array}$ \\
\hline & & Testagem & $\begin{array}{c}\text { teste objetivo e de ensaio } \\
\text { (diagnóstico) }\end{array}$ \\
\hline & & Entrevista & Fichas \\
\hline & \multirow{2}{*}{ 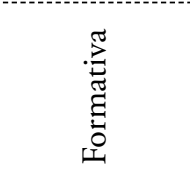 } & Testagem & $\begin{array}{c}\text { testes com referência a } \\
\text { critérios }\end{array}$ \\
\hline & & Observação & $\begin{array}{l}\text { Sistemas de categorias, } \\
\text { escalas, fichas etc. }\end{array}$ \\
\hline & \multirow{2}{*}{ 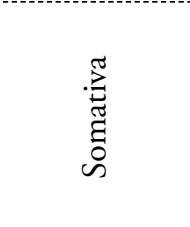 } & Testagem & $\begin{array}{c}\text { testes objetivos e de } \\
\text { ensaio }\end{array}$ \\
\hline & & $\begin{array}{l}\text { observação e } \\
\text { entrevista de } \\
\text { sondagem }\end{array}$ & escalas, fichas etc. \\
\hline
\end{tabular}

Continuação $\rightarrow$ 


\begin{tabular}{|c|c|c|c|}
\hline $\begin{array}{l}\text { Objetivos } \\
\text { (domínio) }\end{array}$ & $\begin{array}{l}\text { Modalidades } \\
\text { de avaliaçáo }\end{array}$ & Técnica aconselhada & Instrumentos e recursos \\
\hline \multirow{8}{*}{$\sum_{\substack{1\\
}}^{0}$} & \multirow{4}{*}{ 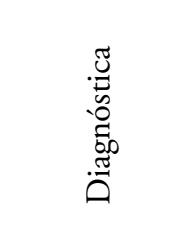 } & Testagem & testes psicológicos \\
\hline & & Sociometria & Sociograma \\
\hline & & Observação & $\begin{array}{l}\text { sistema de categorias, } \\
\text { escalas, anedotários etc. }\end{array}$ \\
\hline & & Questionário & Questionário \\
\hline & \multirow{2}{*}{ 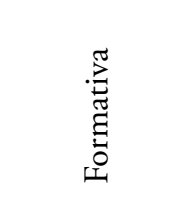 } & Observação & $\begin{array}{c}\text { sistema de categorias, } \\
\text { escalas etc. }\end{array}$ \\
\hline & & Testagem & teste de atitudes etc. \\
\hline & \multirow[t]{2}{*}{ 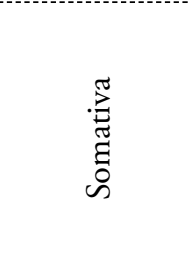 } & Observação & $\begin{array}{c}\text { fichas de } \\
\text { acompanhamento, } \\
\text { inventários (interesse), } \\
\text { escalas de atitudes. }\end{array}$ \\
\hline & & Testagem & $\begin{array}{l}\text { testes objetivos, de } \\
\text { atitude, atençáo etc. }\end{array}$ \\
\hline \multirow{7}{*}{ 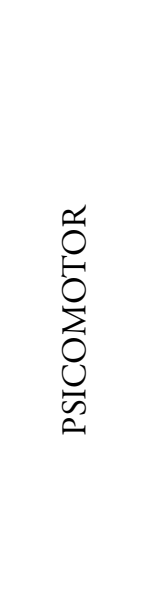 } & \multirow{3}{*}{ 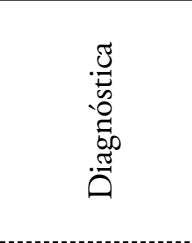 } & Observação & $\begin{array}{c}\text { escalas, sistema de } \\
\text { categorias, anedotários }\end{array}$ \\
\hline & & Testagem & $\begin{array}{c}\text { teste objetivo e de ensaio } \\
\text { (diagnóstico) }\end{array}$ \\
\hline & & Entrevista & Fichas \\
\hline & \multirow{2}{*}{ 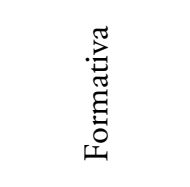 } & Testagem & $\begin{array}{c}\text { testes com referência a } \\
\text { critério }\end{array}$ \\
\hline & & Observação & $\begin{array}{c}\text { sistema de categorias, } \\
\text { escalas etc. }\end{array}$ \\
\hline & \multirow{2}{*}{ 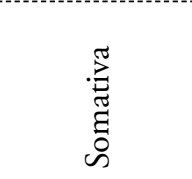 } & Testagem & $\begin{array}{c}\text { testes objetivos e de } \\
\text { ensaio }\end{array}$ \\
\hline & & Observação & escala, fichas etc. \\
\hline
\end{tabular}

Fonte: SANT'ANNA et al., 1993 
de parecer uma repetição do sistema tradicional de ensino, o resumo da nota mostra ao aluno que ela foi gerada conforme o caminho trilhado por ele.

Os objetivos observados na figura 1 são exemplos de como objetivos afetivos podem ser inclusos em sala de aula de forma bem simples ao usarmos um instrumento tecnológico como esse. Objetivos do domínio cognitivo também podem ser usados com esse recurso, possibilitando ao professor maior controle e eficiência do seu trabalho. O próximo exemplo é sobre o uso de objetivos traçados pensando a aquisição de habilidades orais. Observa-se, assim como no último exemplo, a disposição dos objetivos no canto esquerdo, bem como as habilidades adquiridas ou não ao longo da escala de cores. Outro ponto importante a ser levantado, é que o professor, caso julgue necessário, pode aumentar a escala e estabelecer novos critérios.

Fig. 2 - Sistema de rubricas, exemplo de avaliação oral

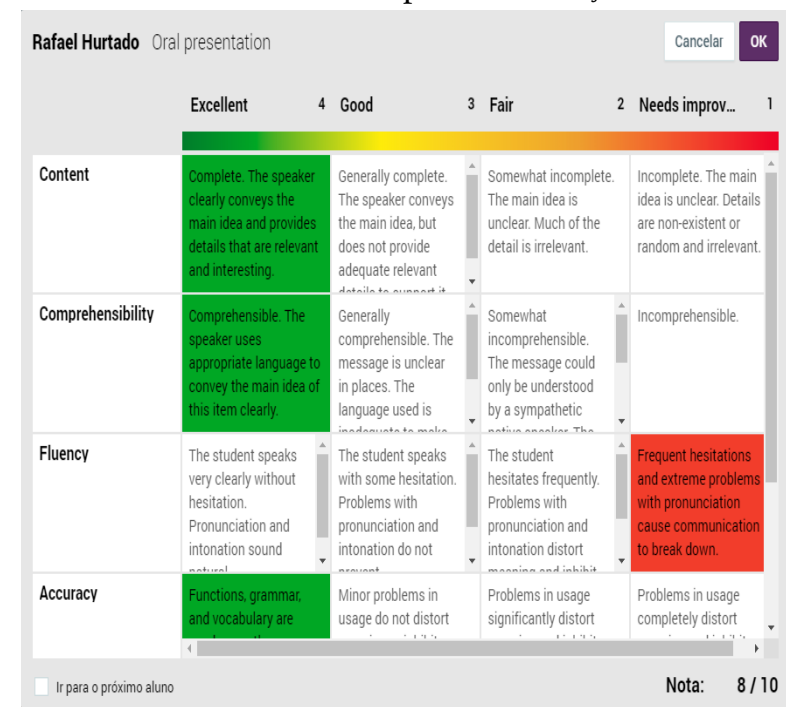

Fonte: Additio. Disponível em: https://edrubrics.additioapp.com/items. Acesso em: 08 de maio 2020.

\section{Análise da Plataforma Addlitio: avanço nos procedimentos de avaliação}

Conforme postula Floch (2001), a semiótica reconhece três sistemas de linguagem: os sistemas simbólicos, os sistemas semióticos e os semi-simbólicos. A plataforma Additio, analisada aqui, configura um sistema 
semi-simbólico, pois o sistema representa, do ponto de vista semiótico, as pinturas, fotografias, infográficos, entre outras manifestações textuais, predominantemente imagéticas. Sobre o plano da expressão e o plano do conteúdo, importantes na nossa análise, Floch (2001, p. 09) afirma:

Para a semiótica, o sentido resulta da reunião, na fala, na escrita, no gesto ou no desenho, de dois planos que toda linguagem possui: o plano de expressão e o plano do conteúdo. O plano da expressão é o plano onde as qualidades sensíveis que possui uma linguagem para se manifestar são selecionadas e articuladas entre elas por variaçóes diferenciais. $\mathrm{O}$ plano do conteúdo é o plano onde a significação nasce das variaçôes diferenciais graças as quais cada cultura, para pensar o mundo ordena e encadeia ideias e discurso.

Entretanto, estamos falando de uma plataforma virtual, um texto em que há a manifestação verbal e visual. Nesse sentido, é necessário delimitar a metodologia utilizada. Nesse caso, adentramos a semiótica plástica. A escolha justifica-se pelo fato de que a Additio é caracterizada predominantemente por imagens visuais. Os textos verbais aparecem pouco, apenas para denotar espaços de configuração da plataforma, de identificação de ícones, e aparecem em forma de data, inserida pelo próprio usuário.

Em relação à concepção de texto, Fiorin (1995) lembra que a semiótica se constitui como uma teoria geral do texto, seja ele manifestação verbal, visual, ou mesmo, combinação dessas modalidades. A palavra imagem, de acordo com Pietroforte (2011), é polissêmica, podendo causar confusóes, pois a imagem é tudo o que se pode ver, e isso inclui a palavra escrita. Antes de ser ouvida, ela entra em nosso campo de visão. Dessa forma, a questão é como lidamos com o plano da expressão da imagem visual sem confundi-la com a imagem do conteúdo associada a ela. Sobre isso, tomemos o exemplo de Pietroforte (2011, p. 33):

O desenho de uma árvore, por exemplo, é formado por meio de categorias plásticas, pois nele há cromatismo e forma, dispostos numa topologia - trata-se da imagem vista -, mas reconhecer nesse significante uma relaçáo com o conceito de árvore diz respeito ao plano de conteúdo, pois são categorias semânticas que definem o conceito de árvore - tratase da imagem imaginada. Construída por meio de formas semânticas, a imagem do conteúdo tem propriedades conceituais que, quando textualizadas em semiótica plástica, passam pelo processo de manifestação em que categorias do conteúdo sáo traduzidas em categorias plásticas. 
Observando a fala do autor, podemos dizer que as imagens da plataforma educacional utilizadas para esta análise são expressas por categorias plásticas, a serem evidenciadas mais adiante. Por uma questão didática, dividimos a análise da plataforma em alguns espaços: espaço de login, página inicial e área do professor.

Fig. 3 - Espaço de login da plataforma

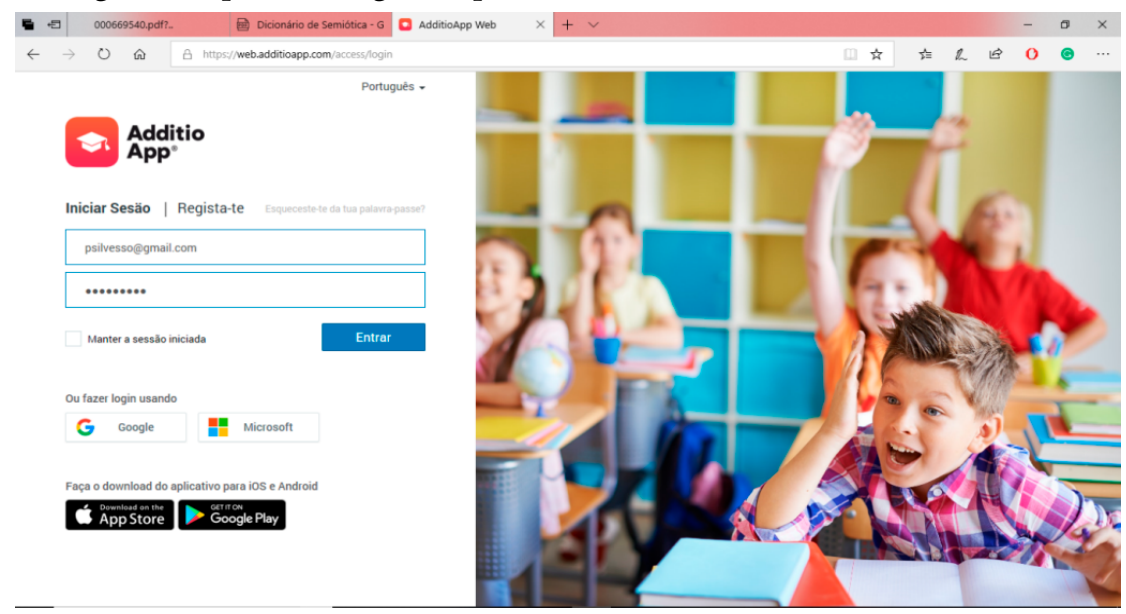

Fonte: Additio. Disponível em: https://web.additioapp.com/. Acesso em: 8 de maio de 2020.

Adiante, descrevemos cada um desses espaços. Para facilitar a leitura, identificamos as imagens por cores e ícones numéricos. $\mathrm{O}$ espaço à esquerda é destinado ao login na plataforma. Ao lado, a imagem que preenche o espaço é uma imagem de uma sala de aula, em que alunos aparecem sentados, alguns com a mão estendida, pressupondo interesse, desejo de participar, motivaçáo. O logo da plataforma, no canto superior esquerdo, é caracterizado pela forma quadrada de cantos arredondados, cor vermelha e a imagem de um capelo ao centro. Observando de forma particular esse logo, podemos traçar algumas categorias, com base na semiótica plástica.

A categoria cromática, na semiótica plástica, diz respeito às cores dispostas na imagem. Na logo, identificamos, dessa forma, o vermelho (quente) e o branco (neutro) que são complementares e formam a oposição claro $\mathrm{x}$ escuro. $\mathrm{O}$ branco foi usado para ressaltar o vermelho, considerado uma cor brilhante. Na próxima categoria, eidética, a logomarca caracteriza-se pela oposição reta $\mathrm{x}$ angular. A forma utilizada é um quadrado de cantos arredon- 
dados que contrasta com a figura do capelo predominantemente angular. Quanto às características topológicas, terceira categoria plástica, a posição do capelo é centralizada em relação ao quadrado, formando uma relação simples categorizado em frente $\mathrm{x}$ atrás. A seguir, mostramos a análise do segundo espaço da plataforma por meio das categorias plásticas estabelecidas a partir dela.

Fig. 4 - Página inicial da plataforma

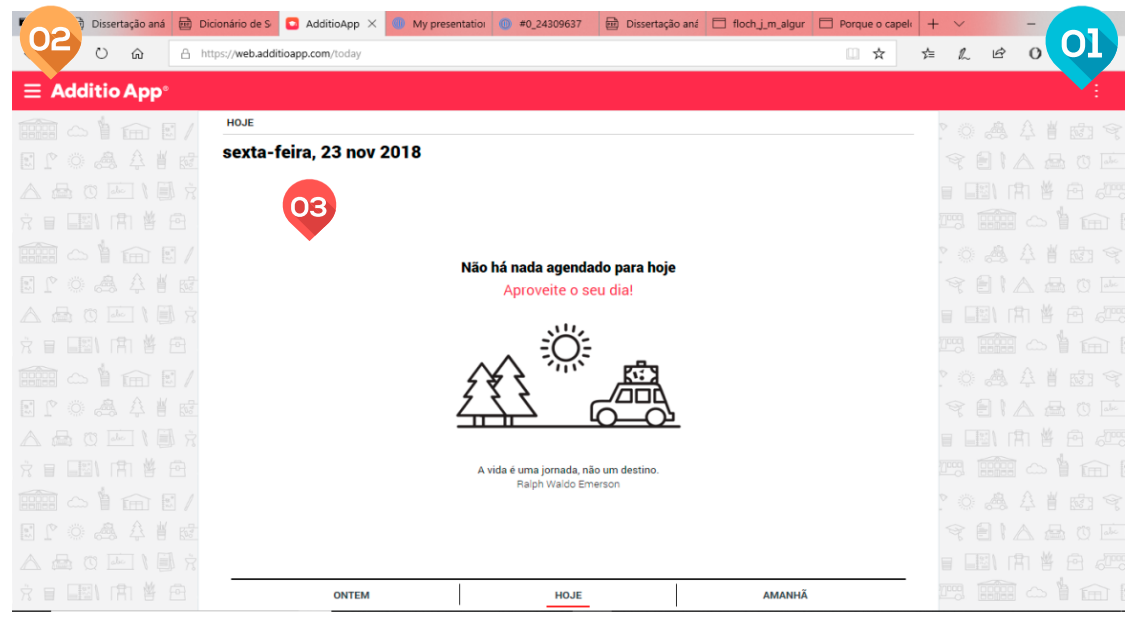

Fonte: Additio. Disponível em: https://web.additioapp.com/. Acesso em: 8 de maio de 2020.

Ao adentrarmos o espaço da plataforma, notamos a repetição dessas categorias. A figura 4, referida, aqui, como página inicial, dispóe de uma faixa vermelha no topo em que se encontra o nome do aplicativo. $\mathrm{O}$ ícone formado por três linhas tracejadas, na cor branca e identificado pelo número 2, constitui o menu de navegação. Notamos um plano de fundo na cor cinza, decorado com ícones pequenos. O segundo plano de fundo sobreposto (marcado como número 3) é branco, contendo algumas informaçóes. Classificamos esse espaço da seguinte maneira:

O cromatismo vermelho (quente) e branco (neutro), presente na plataforma, é complementar, formando a oposição claro x escuro, da mesma forma que analisamos na logo. No plano do conteúdo, no contexto escolar, a projeção dessa categoria remete à cor da caneta utilizada pelo professor em situaçóes específicas: como corrigir uma prova, escrever a nota do aluno, 
escrever um bilhete aos pais. Ademais, lembra a cor dos papéis, do caderno do aluno. Nesse sentido, a cor branca tem seu significado de uso comum modificado pela presença do vermelho.

$\mathrm{Na}$ plataforma, predominam as formas retas, que projetam uma ideia de formalidade, objetividade e sistematização inerentes à noção da prática pedagógica de avaliar, pensando aqui, numa perspectiva mais tradicional de ensino. Além disso, a cor branca do plano de fundo retangular sobreposto ao plano cinza remete à ideia de uma folha branca. A disposiçáo do conteúdo, por sua vez, é simples, priorizando, na página inicial, o calendário e a agenda de tarefas. A data do dia aparece no canto superior esquerdo, posição de destaque em relação aos demais elementos, já que a data é uma informação importante para o enunciatário.

Os demais elementos estão distribuídos de forma centralizada, na seguinte ordem: frase "Não há nada agendado para hoje", frase "Aproveite seu dia!", imagem do carro com as malas de viagem e logo abaixo, uma mensagem motivacional. A primeira frase compreende um informe quanto às tarefas agendadas. A segunda cumpre a função de tranquilizar o enunciatário sobre a ausência de compromissos. A imagem de um carro de passeio, logo depois, portando malas de viagem, reforça ainda mais esse efeito de sentido de relaxamento. Ao final, a frase motivacional convoca o enunciatário a uma reflexão sobre a vida, estabelecendo um vínculo entre plataforma e enunciatário que vai além do vínculo profissional.

Ao observarmos as próximas imagens, exemplo de uma turma fictícia provida pela plataforma Additio, percebemos que os sentidos são gerados, principalmente, na relação com as categorias cromáticas e eidéticas. Isso se deve pela mudança de cores, bem como pela presença de formas arredondadas. Nesse novo espaço, temos duas cores complementares, branco x roxo, e percebemos, mais uma vez, a oposição claro $\mathrm{x}$ escuro. A peculiaridade está no sistema da plataforma, que gera cores aleatórias à medida que se cadastram novas turmas. A cor escura, em oposiçáo ao branco, refletirá no plano do conteúdo que as turmas são diferentes, dispensando o sentido de homogeneidade e padronização. Na categoria eidética, as formas arredondadas, presentes na lateral esquerda da fig. 5, e que servem para identificar os alunos, contrastam com as formas retas. Como dito anteriormente, as formas retas, no espaço da plataforma, denotam objetividade no plano do conteúdo, enquanto as formas arredondadas remetem à subjetividade, ao humano, ao lado sensível presentificado pelos estudantes. 
Fig. 5 - Espaço de cadastro de alunos e notas

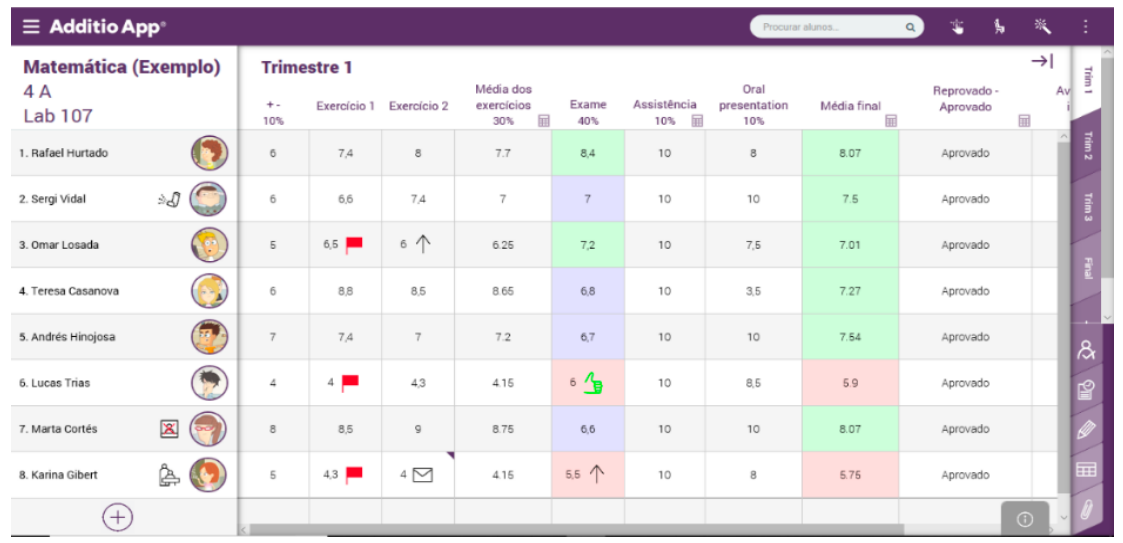

Fonte: Additio. Disponível em: https://web.additioapp.com/. Acesso em: 8 de maio de 2020.

Fig. 6 - Alunos

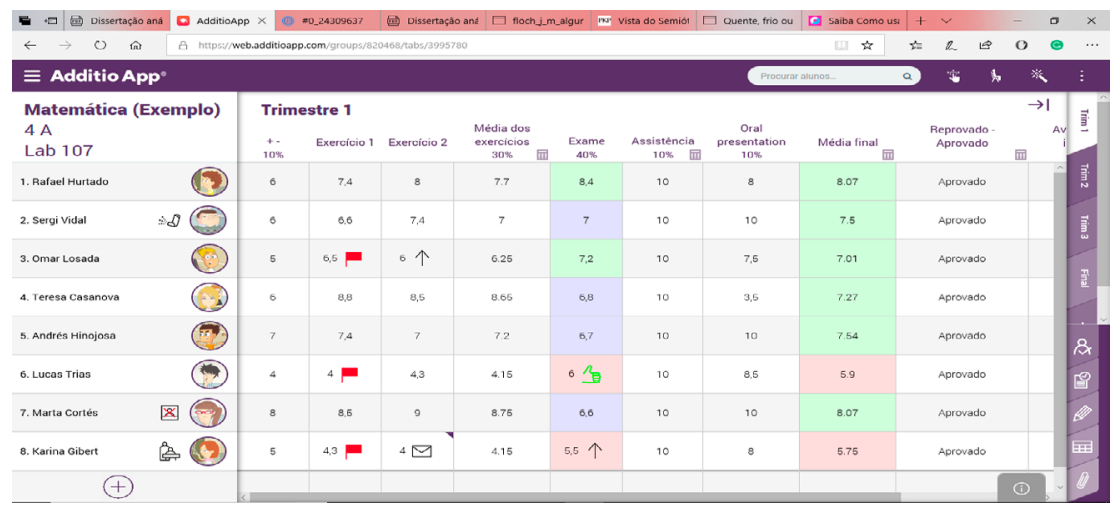

Fonte: Additio. Disponível em: https://web.additioapp.com/. Acesso em: 8 demaio de 2020.

Resumindo o que foi colocado aqui, até o momento, traçamos os seguintes quadros esquemáticos: 
Quadro esquemático 1 - Logotipo Additio

\begin{tabular}{|c|c|c|}
\hline plano da expressão & categoria cromática & claro x escuro \\
& categoria topológica & reto x arredondado \\
plano do conteúdo & figuras do discurso & $\begin{array}{c}\text { formação educás } \\
\text { realização educacional }\end{array}$ \\
\hline
\end{tabular}

Fonte: autoria nossa.

Quadro esquemático 2 - Página de Login

\begin{tabular}{|c|c|c|}
\hline \multirow{2}{*}{ plano da expressáo } & categoria cromática & claro x escuro \\
& categoria topológica & reto x arredondado \\
\hline plano do conteúdo & figuras do discurso & $\begin{array}{c}\text { ambiente de motivaçáo, } \\
\text { aprendizagem }\end{array}$ \\
\hline
\end{tabular}

Fonte: autoria nossa.

Quadro esquemático 3 - Página Inicial

\begin{tabular}{|c|c|c|}
\hline plano da expressão & categoria cromática & claro x escuro \\
& categoria topológica & reto x arredondado \\
plano do conteúdo & figuras do discurso & $\begin{array}{c}\text { Práticas educacionais, } \\
\text { organizaçáo de rotinas }\end{array}$ \\
\hline
\end{tabular}

Fonte: autoria nossa. 
Quadro esquemático 4 - Espaço de cadastro de alunos e notas

\begin{tabular}{|c|c|c|}
\hline plano da expressäo & $\begin{array}{l}\text { categoria cromática } \\
\text { categoria eidética } \\
\text { categoria topológica }\end{array}$ & $\begin{array}{l}\text { claro x escuro } \\
\text { reto x arredondado } \\
\text { frente x atrás }\end{array}$ \\
\hline plano do conteúdo & figuras do discurso & $\begin{array}{c}\text { Avaliação da } \\
\text { aprendizagem, níveis de } \\
\text { aprendizagem, sanção }\end{array}$ \\
\hline
\end{tabular}

Fonte: autoria nossa.

Ao integrar a essa análise as noções de competência, modalidade e valor, estamos trabalhando com o plano do conteúdo do texto. O sujeito pressuposto nessa narrativa poderia ser um professor que utiliza a plataforma, um acadêmico com o objetivo de testá-la, um desenvolvedor de sistemas, entre outros. Entretanto, o objetivo da plataforma, conforme disposto pelos desenvolvedores, pressupóe um sujeito do meio escolar, provavelmente um professor: "Uma plataforma educacional desenhada para sua escola, alunos e família" ${ }^{4}$ (ADDITIO, tradução nossa). Trabalhamos com a ideia de sujeito professor que utilizará a plataforma com as finalidades que se apresentam no quadro esquemático: práticas educacionais, organização de rotinas, entre outros.

As modalizaçóes do fazer são responsáveis pela competência do sujeito, sendo o objeto de valor, também, definidor das paixóes do sujeito. No espaço de login da plataforma, a imagem disposta no canto direito representa um objeto investido de valor eufórico, pois retrata o espaço de uma sala de aula em que estudantes estão supostamente participando ou querendo participar de algo, já que estão com a mão levantada e sorrindo.

Ao associarmos a imagem aos demais elementos, podemos dizer que ela suscita no sujeito do login, o entusiasmo em fazer o login. Nesse sentido, o entusiasmo é marcado pela possibilidade de conjunção com o objeto. Caso o sujeito realize o login, ele tem a possibilidade de obter o que a imagem promove: estudantes motivados. Temos, então, nesse primeiro momento, um sujeito cuja competência é modalizada pelo querer-fazer.

Ao entrar o segundo espaço, esse se mostra como o local de rotina do sujeito professor, que poderá visualizar as suas tarefas agendadas. A agenda é a ferramenta pela qual o sujeito pode garantir organização e, consequen-

4 "The school management system for your school, students and families" (texto original). 
temente, a conjunção com o objeto de valor, pois terá mais controle sobre o que aconteceu, o que está acontecendo e o que deve ser realizado. Nesse caso, a competência do sujeito é modalizada por um poder-fazer.

Novamente, nos demais espaços, as ferramentas de gestão funcionam como meio garantidor da conjunção entre sujeito e objeto de valor, já que modalizam a competência em um poder-fazer. $\mathrm{O}$ cadastro de alunos promove o controle, o cadastro de avaliaçóes possibilita prever atividades. Estamos, portanto, diante de um sujeito que quer ser organizado, por isso utiliza a plataforma, e um sujeito que pode ser organizado, pois a plataforma garante os recursos necessários.

\section{Conclusáo}

Porque tomaram os gileaditas aos efraimitas os vaus do Jordão; e sucedeu que, quando algum dos fugitivos de Efraim dizia: Deixai-me passar; então os gileaditas perguntavam: És tu efraimita? E dizendo ele: Não, Então lhe diziam: Dize, pois, Chibolete; porém ele dizia: Sibolete; porque não o podia pronunciar bem; então pegavam dele, e o degolavam nos vaus do Jordão; e caíram de Efraim naquele tempo quarenta e dois mil. (Juízes 12)

A passagem acima compõe ilustração de diversos autores (SANT'ANNA et al., 1993) quando se referem às práticas avaliadoras comuns da escola, nesse caso, avaliação somativa. Essa impressão de imparcialidade e puniçáo quanto ao erro, pode causar no leitor deste trabalho significativo impacto. Desde o início, não ocultamos o desejo de evidenciar a ausência do afeto no processo de aprendizagem, pelo contrário, expomos reflexôes sobre a avaliação, desde a sua concepção mais simples dicionarizada, passando por uma definição semiótica, até os paradigmas que ditam as funções da avaliação. Mostramos, ainda, como a avaliação somativa não pode ser usada com exclusividade no fazer pedagógico, pois constituí parte do processo avaliativo. É nesse sentido que o uso de ferramentas digitais, como apontado, possibilita o trabalho com mais de um tipo de avaliação e pode auxiliar no uso de objetivos afetivos.

Ao falarmos da plataforma Additio, falamos sobre a sua interface, como funciona o cadastramento de avaliaçóes, como a plataforma pode funcionar como ficha de acompanhamento e, então, iniciamos a análise 
semiótica da plataforma. A análise segue o modelo proposto pela semiótica plástica, e, por isso, observamos três categorias: cromáticas, eidéticas e topológicas. As figuras selecionadas para a análise foram: página de login, página inicial e espaço de cadastro de alunos e notas. O quadro esquemático, logo após, serve como resumo da análise. Ao final, analisamos brevemente o plano do conteúdo da plataforma e trabalhamos com um sujeito pressuposto, o professor. A análise evidenciou a interação sujeito e objeto de valor no contexto da plataforma; mais importante talvez, seja perceber que o processo de aprendizagem pressupóe um percurso que nos leva da enunciação de objetivos até a avaliação, para então, repetir-se incansavelmente, um percurso que podemos considerar clássico. Se observarmos os debates mais recentes sobre a avaliaçáo, o cenário tem desenhado uma nova perspectiva (CARVALHO, 2018): começamos pela avaliação, continuamos nela e encerramos o processo, também, com ela. Este artigo procurou evidenciar que a avaliação deve nortear nosso trabalho pedagógico e fazer sentir as muitas ausências no ensino. Se o afeto tem sido a principal ausência, entregamos ao leitor uma pequena mostra de como podemos contemplá-lo por meio de recursos tecnológicos.

\section{Referências}

ADDITIO. Disponível em: https://www.additioapp.com/en. Acesso em: 13 de jun. 2019.

BLOOM, B. S. Taxionomia de objetivos Educacionais: domínio afetivo. Porto Alegre, RS: Editora Globo, 1973.

CARVALHO, Robson Santos de. Ensinar a ler, aprender a avaliar: avaliação diagnóstica das habilidades de leitura. São Paulo: Parábola, 2018.

DICIO. Dicionário online de português. Disponível em: https://www.dicio. com.br/. Acesso em: 07 de jun. 2019.

FERREIRA, A. T. B; LEAL, T. F. Avaliação na escola e ensino da língua portuguesa: introduçáo ao tema. In: MARCURSCHI, B; SUASSUNA, L. (org.) Avaliação em lingua portuguesa: contribuiçóes para a prática pedagógica. 1. ed. Belo Horizonte, MG: Autêntica, 2007. p.11-26. 
FIORIN, J. L. A noção de texto na semiótica. Organon, Rio Grande do Sul, v.9, n. 23, p. 165-176, jan./jul. 1995. Disponível em: http://seer.ufrgs.br/ index.php/organon/article/view/29370. Acesso em: 12 de jun. 2019.

FLOCH, J. M. Alguns conceitos fundamentais em semiótica geral. São Paulo, SP: Centro de Pesquisas Sociossemióticas, 2001.

GREIMAS, A. J.; COURTÉS, J. Dicionário de semiótica. São Paulo, SP: Contexto, 2008.

LÜCK, H.; CARNEIRO, D. G. Desenvolvimento afetivo na escola: promoção, medida e avaliação. Rio de Janeiro, RJ: Vozes, 1983.

LUCKESI, C. C. Avaliação da aprendizagem escolar: estudos e proposiçóes. São Paulo, SP: Cortez, 2011.

MARTINS, A. C. S; RACILAN, Marcos; SOUZA, V. V. S. O uso de tecnologias digitais na avaliação da aprendizagem. In: BRAGA, Carvalho Fidelis, Junia de et al. (org.). Integrando tecnologias no ensino de inglês nos anos finais do ensino fundamental. São Paulo: Ediçóes SM, 2012

MICHAELIS. Dicionário brasileiro da língua portuguesa. Disponível em: http://michaelis.uol.com.br/busca?id=K742. Acesso em: 29 de jun. 2019.

MORETTO, P. V. Prova. Rio de Janeiro, RJ: lamparina, 2014.

PERRENOUD, P.THURLER, M.G.;MACEDO,L. de;ALESSANDRINI, C. D. As competências para ensinar no século XXI: A formação dos professores e o desafio da Avaliação. Porto Alegre, RS: Artmed, 2008.

PIETROFORTE, A. V. Análise do texto visual: a construção da imagem. São Paulo, SP: Contexto, 2011.

SANT'ANNA F. et al. Planejamento de ensino e avaliação. Porto Alegre, RS: Sagra, 1993.

SAUSSURE, F. de. Curso de linguistica geral. São Paulo: Cultrix, 2003.

SUASSUNA, L. Paradigmas de avaliação: uma visão panorâmica. In: MARCURSCHI, B; SUASSUNA, L. (org.). Avaliação em língua portuguesa: contribuiçôes para a prática pedagógica. Belo Horizonte, MG: Autêntica, 2007. p. 27-44.

Recebido em: 29 jun. 2019.

Aceito em: 12 nov. 2019. 